\title{
T-cell mediated autoimmunity to the insulinoma-associated protein 2 islet tyrosine phosphatase in type 1 diabetes mellitus
}

Francesco Dotta $^{1}$, Sabrina Dionisi ${ }^{1}$, Vissia Viglietta ${ }^{1}$, Claudio Tiberti ${ }^{1}$, Maria Cristina Matteoli ${ }^{2}$, Marco Cervoni ${ }^{3}$, Carla Bizzarri ${ }^{4}$, Giovanni Marietti ${ }^{4}$, Manuela Testi ${ }^{5}$, Giuseppe Multari ${ }^{3}$, Lucio Lucentini ${ }^{2}$ and $^{2}$ Umberto Di Mario ${ }^{1}$

${ }^{1}$ Department of Endocrinology, University 'La Sapienza', Rome, Italy, ${ }^{2}$ Ospedale 'Bambino Gesù', Palidoro, Italy, ${ }^{3}$ Department of Pediatrics, University 'La Sapienza', Rome, Italy, ${ }^{4}$ Department of Pediatrics, University Cattolica S. Cuore, Rome, Italy and ${ }^{5}$ Immunohematology Unit, Section on Molecular Biology, Centro Nazionale Trasfusione Sangue, Croce Rossa Italiana, Rome, Italy

(Correspondence should be addressed to F Dotta, c/o D.E.M. Foundation, Largo Marchiafava 1, O0161, Rome, Italy)

\begin{abstract}
The target molecules of the T-cell response in type 1 diabetes, despite their pathogenic importance, remain largely uncharacterized, especially in humans. Interestingly, molecules such as insulin and glutamic acid decarboxylase (GAD) have been shown to be a target not only of autoantibodies, but also of autoreactive T-lymphocytes both in man and in the non-obese diabetic (NOD) mouse. In the present study we aimed to determine the existence of a specific T-cell response towards the insulinomaassociated protein 2 (IA-2) islet tyrosine phosphatase, a recently identified autoantigen which is the target of autoantibodies strongly associated with diabetes development. Human recombinant IA-2 produced in Escherichia coli, was tested for its reactivity with peripheral blood lymphocytes obtained from 16 newly diagnosed type 1 diabetic patients and from 25 normal controls, 15 of whom were HLADR-matched. A T-cell proliferation assay was performed in triplicate employing freshly isolated cells in the absence or in the presence of the antigen to be tested (at two different concentrations: $2 \mu \mathrm{g} / \mathrm{ml}$ and $10 \mu \mathrm{g} / \mathrm{ml}$ ). A specific T-cell proliferation (defined as a stimulation index (S.I.) $\geq 3$ ) was observed against IA-2 used at a concentration of $10 \mu \mathrm{g} / \mathrm{ml}$ (but not of $2 \mu \mathrm{g} / \mathrm{ml}$ ) in 8/16 diabetic patients, in 1/15 HLA-DR-matched control subjects $(P<0.01$ by Fisher exact test) and in $0 / 10$ of the remaining normal individuals. A statistically significant difference $(P<0.003$ by Mann-Whitney U test) was also observed in S.I. values between patients $(3.1 \pm 1.4)$ and HLA-DR-matched controls $(1.7 \pm 0.54)$ employing IA- 2 at a concentration of $10 \mu \mathrm{g} / \mathrm{ml}$. However, when IA- 2 was used at a concentration of $2 \mu \mathrm{g} / \mathrm{ml}$, the difference in S.I. between patients $(1.65 \pm 0.8)$ and controls $(1.0 \pm 0.3)$ did not reach statistical significance. In conclusion, these data show the presence of a specific, dose-dependent T-lymphocyte response against the IA-2 islet tyrosine phosphatase at the onset of type 1 diabetes. Consequently, this molecule appears to be a target not only at the B-lymphocyte but also at the T-lymphocyte level, reinforcing the potential pathogenic role of this autoantigen in the islet destructive process.
\end{abstract}

European Journal of Endocrinology $141272-278$

\section{Introduction}

A number of studies $(1,2)$ have clearly indicated that the progressive autoimmune islet beta cell destruction leading to insulin-dependent (type 1) diabetes mellitus (IDDM) is a T-lymphocyte-mediated event. However, despite the pathogenic importance of the T-cell response in type 1 diabetes, the target molecules of autoreactive T-cells remain largely uncharacterized, especially in humans. Autoantigens so far identified in autoimmune diabetes have been discovered from diseaseassociated autoantibodies $(3,4)$ which, although representing important tools for the prediction of future diabetes development, have no pathogenic significance since they do not directly cause any islet damage. Interestingly, molecules such as insulin (5) and glutamic acid decarboxylase (GAD) (6) have been shown to be the target not only of autoantibodies, but also of autoreactive T-lymphocytes both in man and in an animal model of autoimmune diabetes such as the non-obese diabetic (NOD) mouse (7). In addition to insulin and GAD, other molecules expressed in beta-cell secretory granules and mitochondria (8) with a molecular weight around $38 \mathrm{kDa}$ may be important autoantigens in the T-cell response associated with type 1 diabetes.

In the present study we aimed to investigate the existence of a specific T-cell response towards the insulinoma-associated protein 2 (IA-2) islet tyrosine phosphatase, an autoantigen which is the target of 
autoantibodies highly associated to diabetes development $(9,10)$. To this end, human recombinant IA-2 produced in Escherichia coli, was tested for its reactivity with peripheral blood lymphocytes obtained from newly diagnosed type 1 diabetic patients and from HLA-DR-matched normal control individuals.

\section{Materials and methods}

\section{Patients}

Peripheral blood mononuclear cells (PBMC) were isolated by Ficoll-Hypaque (Sigma, St Louis, MO, USA) density centrifugation from heparinized blood obtained from (i) sixteen newly diagnosed type 1 diabetic patients within one week of the diagnosis ( 8 males and 8 females, age range 3.5-37 years); according to HLA-DR typing, 3 subjects were DR 3/4, 1 was DR 3/3, 1 was DR 4/4, 4 were DR 4/x, 5 were DR 3/x, 1 was DR 15/12 and one could not be typed for technical reasons, and (ii) twenty-five normal control subjects with no family history for type 1 diabetes matched for sex and age with group (i) patients, comprising a subgroup of 15 individuals HLA-DR-matched with 15 type 1 diabetic subjects.

All subjects were studied for the presence of the following diabetes-associated autoantibodies: anti-insulin (insulin autoantibodies (IAA)), anti-GAD-65 (GAD-65 autoantibodies (GAA)) and anti-IA-2/ICA512bdc islet protein.

\section{HLA-DR typing}

HLA-DR molecular typing was performed using a PCR/ SSP method. Briefly, high molecular weight DNA, extracted from EDTA-frozen blood samples by a salting out technique, was amplified employing a set of 24 primer solutions containing DRB allele- and groupspecific primers. The PCR-amplified DNA fragments were separated by agarose gel electrophoresis and visualized by ethidium bromide staining. The absence or the presence of a specific amplification product defined the specificity of the sample.

\section{Determination of anti-insulin autoantibodies}

The presence of IAA has been analyzed employing a competitive fluid phase radioimmunoassay as previously described (11).

\section{Determination of GAD-65 autoantibodies}

GAA were measured in triplicate by radioassay, using in vitro transcribed and translated recombinant human GAD (65 kDa isoform) followed by precipitation with protein A-sepharose (12). The interassay coefficient of variation in our laboratory is $6.5 \%$. The results are expressed as an index calculated from the counts per minute for the test sample and the positive and negative control samples.

\section{Determination of anti-ICA 512 bdc autoantibodies}

ICA512bdc autoantibodies were measured in duplicate using an assay format similar to that for GAA but with in vitro transcribed and translated ICA $512 \mathrm{bdc}$ (13). The interassay coefficient of variation is $11.7 \%$. ICA $512 \mathrm{bdc}$ is a new construct that includes amino acid residues 256 through 979 (compared with amino acids 389 through 937 for the originally described ICA512, and amino acids 1 through 979 for the full-length IA-2 molecule). The results are expressed as an index calculated from the counts per minute for the test sample and the positive and negative control samples.

\section{Preparation of the IA-2 molecule}

cDNA representing the full-length open reading frame for human IA-2, cloned into the vector pGEM-4Z (Promega, Madison, WI, USA), was expressed as a fusion protein with a biotin-labeled tag sequence and purified on streptavidine agarose as previously described (14).

\section{T-cell proliferation assay}

A T-cell proliferation assay was performed in triplicate in 96-well round bottom plates (Falcon, Becton Dickinson, Franklin Lakes, NJ, USA) employing freshly isolated PBMC at a concentration of 150000 cells/well, using RPMI 1640 (Sigma) containing 10\% human autologous serum. After incubation for $72 \mathrm{~h}$ at $37^{\circ} \mathrm{C}$ in the absence or in the presence of the antigen to be tested (two different IA-2 concentrations were used: $2 \mu \mathrm{g} / \mathrm{ml}$ and $10 \mu \mathrm{g} / \mathrm{ml}$ ), $1 \mu \mathrm{Ci} /$ well $\left[{ }^{3} \mathrm{H}\right]$ thymidine (Amersham International, Amersham, Bucks, UK) was added and left to incubate for $16 \mathrm{~h}$, followed by determination of thymidine incorporation by liquid scintillation counting. Tetanus toxoid (Calbiochem, San Diego, CA, USA) at a concentration of $2.5 \mu \mathrm{g} / \mathrm{ml}$ and phytohemagglutinin (PHA) (Difco, Detroit, MI, USA) at a concentration of $20 \mu \mathrm{g} / \mathrm{ml}$ were used as positive controls for antigenspecific and aspecific T-cell stimulation respectively. A specific T-cell proliferation was defined as a stimulation index (S.I.) $\geq 3$, calculated as the ratio between c.p.m. PBMC in the presence of the antigen and c.p.m. PBMC in medium alone. In addition, the first 8 patients and 9 controls were tested for T-cell reactivity in a 'blind' manner (without knowing the antigen preparation) as part of the First Workshop on Autoreactive T Cells in IDDM. In this workshop T-cell reactivity towards a panel of different antigens such as insulin, GAD-65, casein A1 and A2, p69, p277 and C-peptide was tested.

\section{Statistical analysis}

Mann-Whitney U test was used to compare the T-cell responses against IA-2 among the different groups of patients. Fisher's exact test with Yates correction was 
Table 1 Characteristics of new onset type I diabetic patients studied.

\begin{tabular}{|c|c|c|c|c|c|c|}
\hline Patient & $\begin{array}{c}\text { Age } \\
\text { (years) }\end{array}$ & $\begin{array}{l}\text { IAAT } \\
(\mathrm{nU} / \mathrm{ml})\end{array}$ & $\begin{array}{l}\text { GAA } \ddagger \\
\text { (index) }\end{array}$ & $\begin{array}{l}\text { ICA512bdc } \S \\
\text { (index) }\end{array}$ & HLA-DR & $\begin{array}{c}\text { IA-2 T-cel| } \\
\text { (S.I.) }\end{array}$ \\
\hline 1 & 12 & 0.9 & 0.287 & 1.194 & DRB1 ${ }^{*} 03-04$ & 6.7 \\
\hline 2 & 11.5 & 1707 & 0.001 & 0.644 & DRB $1{ }^{*} 01-04$ & 4.5 \\
\hline 3 & 12.5 & 192 & 0.093 & 0.001 & DRB1*15-12 & 4.4 \\
\hline 4 & 16 & 5.5 & 0.827 & 0.84 & DRB1 ${ }^{*} 03-15$ & 3.8 \\
\hline 5 & 3.5 & 76.1 & 0.039 & 0.227 & N.D. & 3.5 \\
\hline 6 & 4 & 51.7 & 0.001 & 0.001 & DRB $1{ }^{*} 03-16$ & 3.4 \\
\hline 7 & 10 & 89 & 0.383 & 0.391 & DRB $1{ }^{*} 03$ & 3.2 \\
\hline 8 & 15 & 1 & 0.376 & 0.03 & DRB1*01-04 & 3.1 \\
\hline 9 & 3.5 & 784 & 0.007 & 0.004 & DRB $1{ }^{*} 01-03$ & 2.7 \\
\hline 10 & 12 & 1174 & 0.388 & 0.001 & DRB $1{ }^{*} 03-04$ & 2.5 \\
\hline 11 & 8.5 & 135 & 0.713 & 1.117 & DRB1 ${ }^{*} 04-15$ & 1.92 \\
\hline 12 & 12 & 6.2 & 0.001 & 0.018 & DRB1 ${ }^{*} 03-04$ & 1.9 \\
\hline 13 & 11 & 231 & 0.068 & 0.565 & DRB $1{ }^{*} 01-04$ & 1.9 \\
\hline 14 & 3.5 & 87.2 & 0.162 & 0.001 & DRB1*03-11 & 1.5 \\
\hline 15 & 10 & 13 & 0.001 & 0.08 & DRB1*04 & 1.5 \\
\hline 16 & 37 & 1 & 0.352 & 0.001 & DRB1 ${ }^{*} 03-10$ & 0.9 \\
\hline
\end{tabular}

† Values above 39 have been considered as positive. $\ddagger$ An index above 0.032 has been considered as positive. $\S$ An index above 0.071 has been considered as positive.

N.D., not determined.

used to compare the frequencies of a positive T-cell response in the different groups of patients. Simple regression analysis was utilized to correlate the T-cell response against IA-2 with a number of parameters such as age, IAA, GAA and ICA512bdc autoantibody levels.

\section{Results}

\section{Autoantibodies (Table 1)}

Among the 16 newly diagnosed type 1 diabetic patients studied, $10(62.5 \%)$ were IAA positive, $10(62.5 \%)$ were GAA positive and 11 (68.8\%) were ICA512bdc positive. All normal controls tested were negative for IAA, GAA and ICA512bdc.

\section{T-cell response against IA-2}

A specific T-cell proliferation was observed (Fig. 1) against IA-2 used at a concentration of $10 \mu \mathrm{g} / \mathrm{ml}$ in $8 / 16$ diabetic patients, in 1/15 HLA-DR-matched control subjects $(P=0.01$ by Fisher exact test $)$ and in 0/10 normal individuals not expressing DR3 or DR4 $(P<0.001$ by Fisher exact test). The only normal control with a positive T-cell response against IA-2 was DRB ${ }^{*} 03-15$. In addition, a statistically significant difference $(P=0.003$ by Mann-Whitney U test) was observed between S.I. values in patients $(3.1 \pm 1.4)$ and in HLA-DR-matched normal controls $(1.7 \pm 0.54)$. Normal individuals not expressing DR3 or DR4 showed an S.I. of $1.1 \pm 0.37$, statistically different from that of new onset type 1 diabetic subjects $(P<0.001$ by Mann-Whitney $\mathrm{U}$ test $)$ but not from

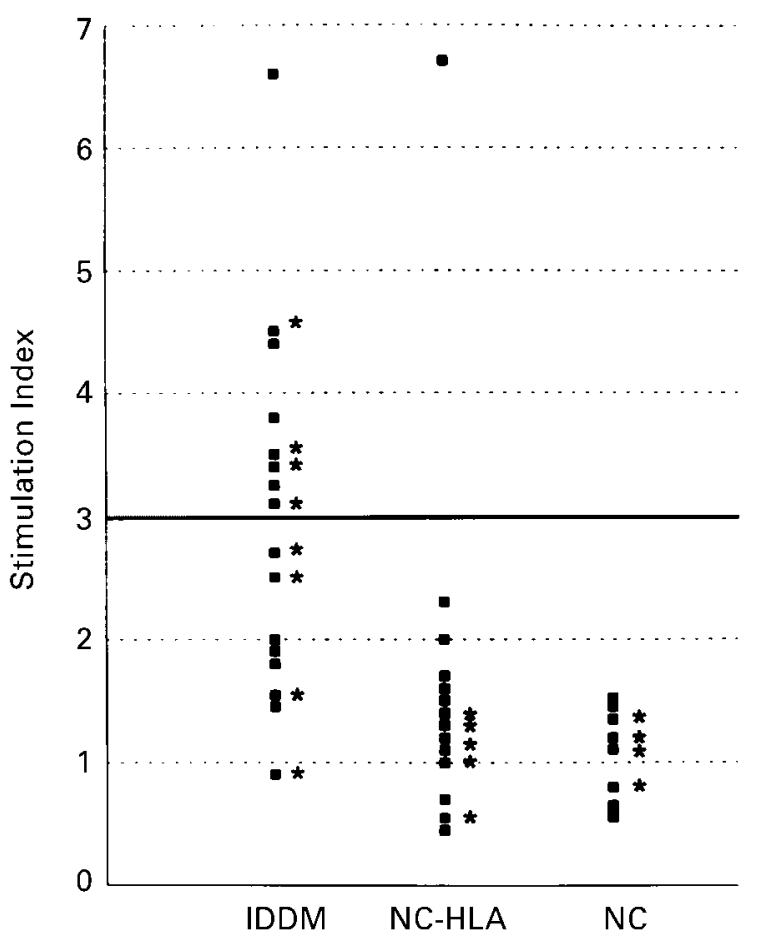

Figure $1 \mathrm{~T}$-cell reactivity against IA-2 in the different groups studied. The stimulation index is calculated as the ratio between c.p.m. PBMC in the presence of the antigen and c.p.m. PBMC in medium alone. The horizontal line represents the limit of positivity $(S . I . \geq 3)$ for T-cell reactivity. A statistically significant difference (by Fisher exact test) was found in the frequency of a specific T-cell response between newly diagnosed type 1 diabetic patients (IDDM) and HLADR-matched normal control subjects (NC-HLA) $(P=0.01)$, and between type 1 diabetic patients and HLA-DR-unmatched (not DR3 nor DR4) normal control subjects $(\mathrm{NC})(P<0.001)$. Asterisks indicate those subjects tested in a 'blind' manner in terms of antigen preparation. 


\section{T-cell response anti-IA-2 \\ Dose-dependency}

Figure 2 T-cell reactivity against IA-2: dose-dependency. PBMC from new onset type 1 diabetic patients $(n=8)$ were tested for reactivity against IA-2 at two different concentrations, $2 \mu \mathrm{g} / \mathrm{ml}$ and $10 \mu \mathrm{g} / \mathrm{ml}$. The horizontal line represents the limit of positivity (S.I. $\geq 3$ ) for T-cell reactivity. Dashed lines connect each individual tested at 2 different antigen concentrations.

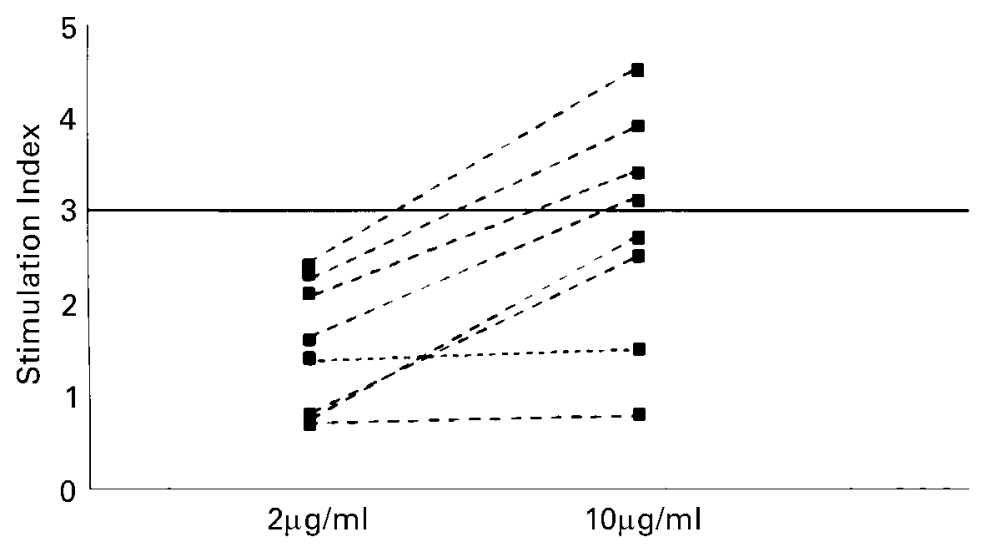

the T cell reactivity against the other molecules tested in a 'blind' manner (Fig. 3) was observed between patients and control subjects.

Finally, no difference was found among the groups of individuals in the T-cell response against tetanus toxoid or PHA (data not shown).

\section{Correlation between T-cell response against IA-2 and diabetes-associated autoantibodies (Figs 4 and 5)}

No correlation was found between a positive T-cell response against IA-2 and positivity and/or levels of IAA (Fig. 4a), GAA (Fig. 4b) and ICA512bdc (Fig. 4c). pants $(1.65 \pm 0.8)$ and controls $(1.0 \pm 0.3)$ did not

\section{T-cell response}

Figure 3 T-cell reactivity against a panel of antigens. PBMC from new onset type 1 diabetic patients $(n=8)$ were tested for reactivity against the following antigens: GAD-65 (grown in E. coli (col), in baculovirus (bac), and in yeast (yst)), IA2 (2 different concentrations), insulin (INS.), p69, p277, C-peptide (C-Pept.), casein A1 (Cas.A1) and casein A2 (Cas.A2). The horizontal line represents the limit of positivity (S.I. $\geq 3$ ) for Tcell reactivity.

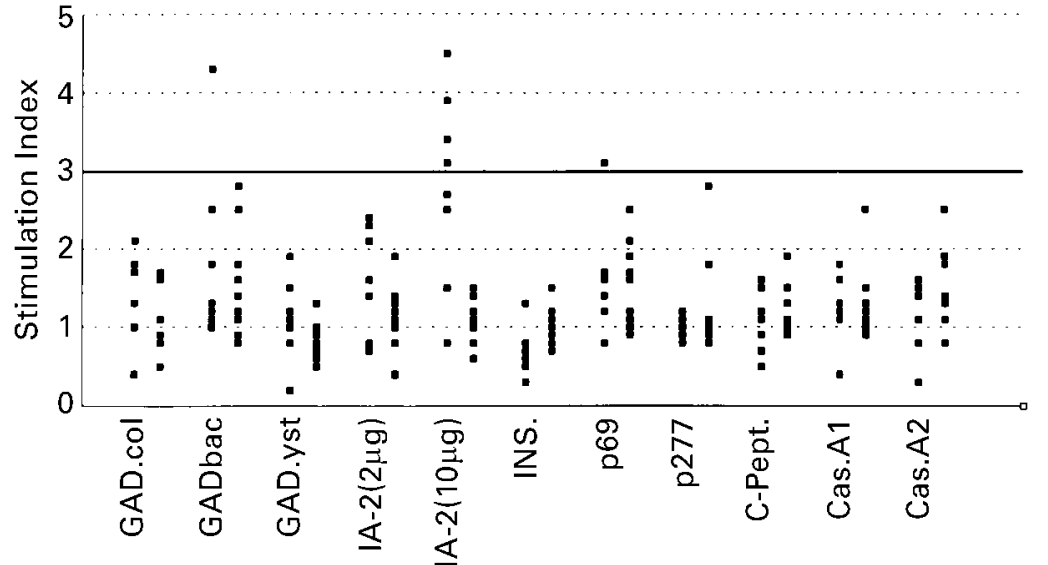


(a) T-cell response anti-IA-2 and Insulin autoantibodies

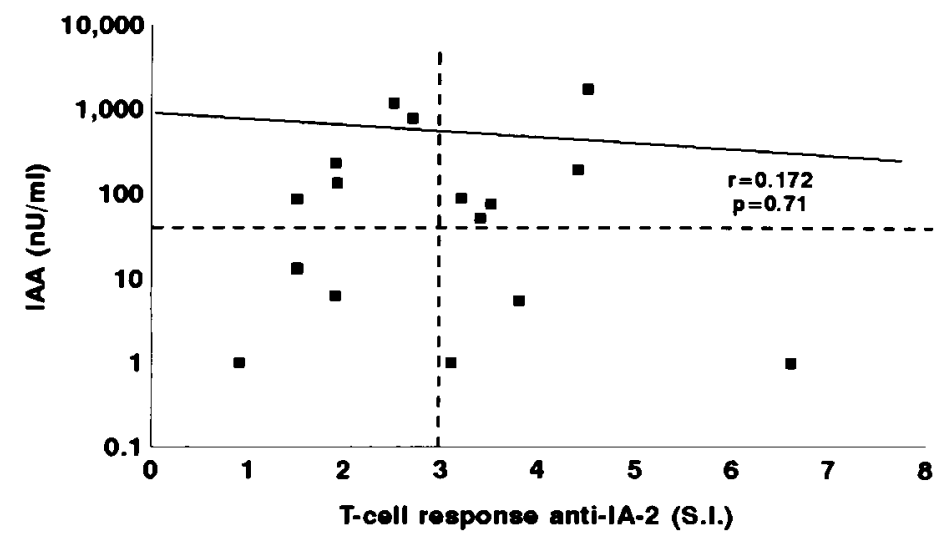

(b) T-cell response anti-IA-2 and GAD65 autoantibodies

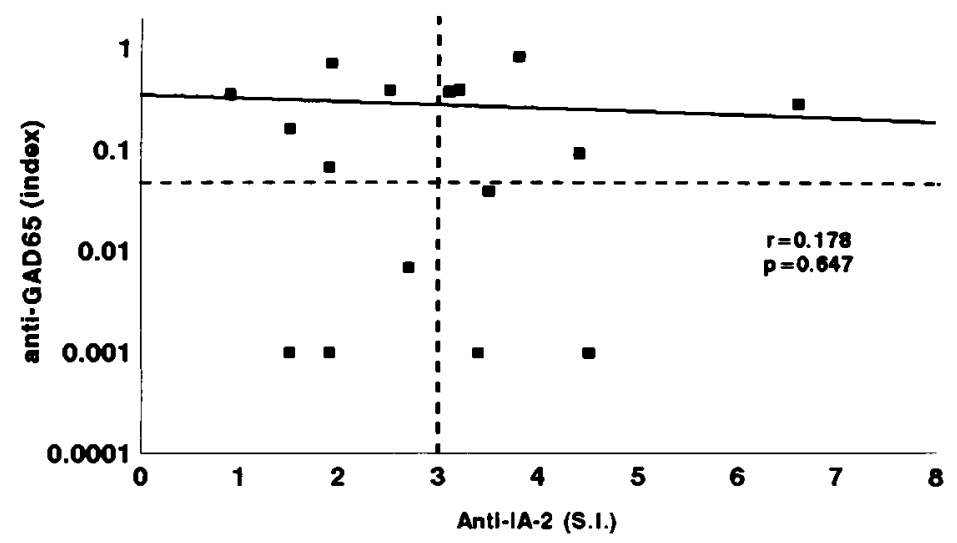

(c) T-cell response anti-IA-2 and ICA512bdc autoantibodies

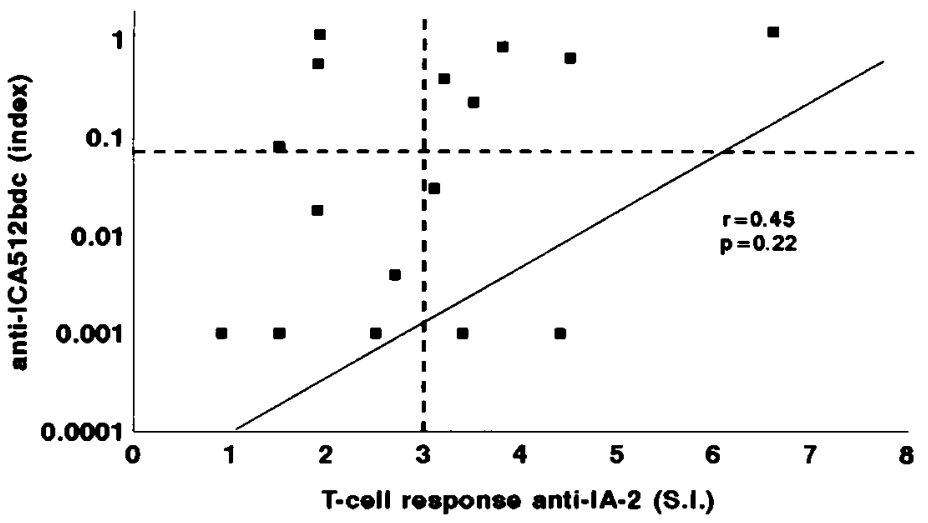

Figure 4 Correlation between T-cell reactivity against IA2 and levels of (a) IAA, (b) GAA and (c) ICA512bdcAb in new onset IDDM patients. The vertical dashed line represents the limit of positivity (S.I. $\geq 3$ ) for T-cell reactivity. The horizontal dashed line indicates the limit of autoantibody positivity. The continuous line indicates the regression line. 


\section{T-cell response anti-IA-2 and age}

Figure 5 Correlation between T-cell reactivity against IA-2 and age in new onset IDDM patients. The vertical dashed line represents the limit of positivity (S.I. $\geq 3$ ) for T-cell reactivity. The continuous line indicates the regression line.

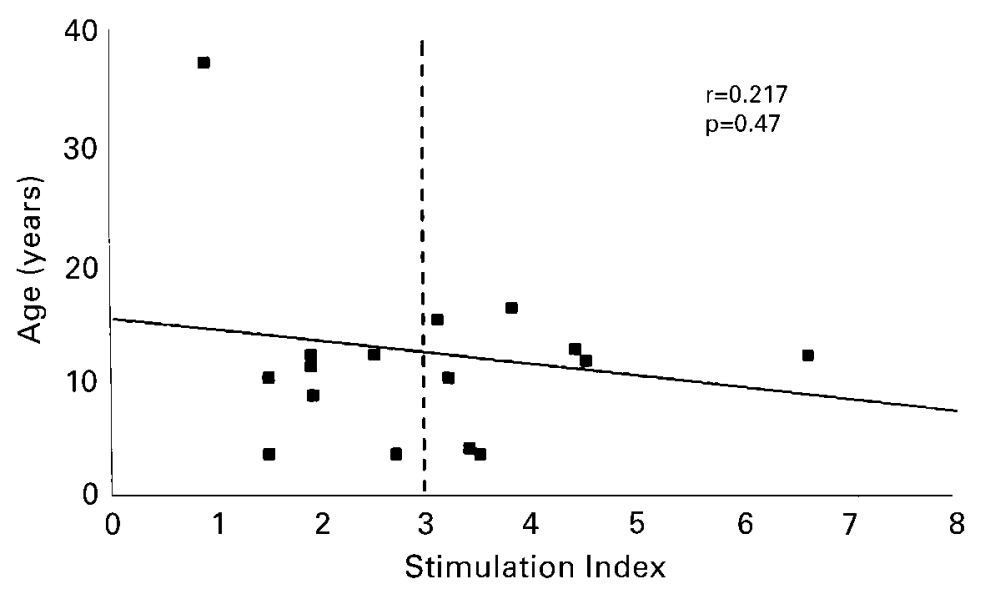

In addition, the T-cell response against IA-2 was not correlated with the age (Fig. 5) or with the sex of the patient.

\section{Discussion}

By analyzing the T-cell response against the islet tyrosine phosphatase IA-2 in peripheral blood lymphocytes from newly diagnosed type 1 diabetic individuals and HLA- and non-HLA-DR matched control subjects, we observed reactive T-lymphocytes against this molecule at a higher frequency in type 1 diabetic patients. This T-cell reactivity was dose dependent and did not correlate with age, sex, HLA-DR type nor with the presence of diabetes-associated autoantibodies $(\mathrm{Ab})$, i.e. IAA, GAA and ICA512bdc-Ab. Cellular immune reactivity towards islet molecules such as insulin, GAD, Imogen 38 and other beta-cell components was reported (15-18) in newly diagnosed type 1 diabetic subjects and in autoantibody-positive relatives by studying peripheral blood lymphocytes. As far as the islet tyrosine phosphatase is concerned, to our knowledge no report of T-cell reactivity against the whole human recombinant IA-2 molecule is to date available, while two reports $(19,20)$ are already published on the ICA512 fragment and on the entire $42 \mathrm{kDa}$ internal domain of the IA-2, showing a prevalence for a positive T-cell response in new onset type 1 diabetic patients and in high risk relatives similar to that which we observed against the whole IA-2 molecule. Differently from the data on the ICA512 fragment which have been generated employing a hybrid molecule with glutathione-S-transferase as fusion protein, in our study the antigen preparation used was represented by the IA-2 molecule alone. The magnitude of the response we observed against IA-2 was lower than that reported towards ICA512; however, this may be due to the shorter incubation ( 3 days vs 5 days) used in our assay. It should be pointed out that in our study all patients were individually HLA-DR matched to a given normal control. In addition, 8 type 1 diabetic patients and 9 controls were tested in a 'blind' manner in terms of antigen preparation. In this way, a significant increase in both frequency and magnitude of T-cell reactivity was observed in patients versus controls, suggesting that the presence of such a reactivity is associated with an ongoing autoimmune response against the pancreatic islet beta-cells, rather than determined by the presence of a diabetes-susceptibility to HLA-DR haplotype itself. No significant correlation between the humoral and cellular immune response against IA-2 has been observed, in parallel with that reported (19, 20) on insulin and on the ICA 512 fragment, but in contrast with the data observed on GAD (16).

It should be considered that, at least in some cases, the PBMC proliferative responses might be due to trace bacterial contaminants deriving from the antigen preparation procedures used in this type of study. Anyway, with regard to this aspect, the difference between patients and controls is difficult to explain by this phenomenon; furthermore, another antigen such as GAD-65, although prepared in E. coli, did not show different proliferative responses from type 1 diabetic patients and controls.

In conclusion, these data show that a specific, dosedependent T-lymphocyte response against the IA-2 islet tyrosine phosphatase is present at the onset of type 1 diabetes, indicating that this molecule represents a target not only at the B-lymphocyte but also at the T-lymphocyte level, reinforcing the potential pathogenic role of this autoantigen in the islet destructive process leading to the disease. 


\section{Acknowledgements}

The IA-2 molecule tested for T-cell reactivity was kindly provided by Dr MR Christie, King's College School of Medicine, London, UK. The technical assistance of Paola Cerrone has been greatly appreciated. This work was supported by grants from the National Research Council of Italy (UD M), the ltalian Society of Diabetology and the Juvenile Diabetes Foundation (F D), the Italian Ministry of Health (LL) and from the D.E.M. Foundation.

\section{References}

1 Tisch R \& McDevitt H. Insulin-dependent diabetes mellitus. Cell 199685 291-297.

2 Katz JD, Wang B, Haskins K, Benoist C \& Mathis D. Following a diabetogenic T cell from genesis through pathogenesis. Cell 1993 74 1089-1100.

3 Atkinson MA \& MacLaren NK. Islet cell autoantigens in insulin dependent diabetes. Journal of Clinical Investigation 199392 1608-1616.

4 Bonifacio E, Lampasona V, Genovese S, Ferrari M \& Bosi E. Identification of protein tyrosine phosphatase-like IA-2 (islet cell antigen 512) as the insulin-dependent diabetes-related 37/40 K autoantigen and a target of islet-cell antibodies. Journal of Immunology 1995155 5419-5426.

5 Wegmann D, Norbury-Glaser M \& Daniel D. Insulin-specific T cells are a predominant component of islet infiltrates in pre-diabetic NOD mice. European Journal of Immunology 199324 18531857.

6 Atkinson MA, Kaufman DL, Campbell L, Gibbs KA, Shah SC \& Bu DF. Response of peripheral blood mononuclear cells to glutamate decarboxylase in insulin-dependent diabetes. The Lancet 1992 $339458-459$.

7 Kaufman DL, Clare-Salzler M, Tian J, Foersthuber T, Ting GS, Robinson P et al. Spontaneous loss of T-cell tolerance to glutamic acid decarboxylase in murine insulin-dependent diabetes. Nature 1993366 69-72.

8 Arden SD, Roep BO, Neophytou PI, Usac EF, Duinkirken G, de Vries RP \& Hutton J. Imogen 38: a novel 38-kD islet mitochondrial autoantigen recognized by $\mathrm{T}$ cells from a newly diagnosed type 1 diabetic patient. Journal of Clinical Investigation 199697551 561.
9 Lan MS, Lu J, Goto Y \& Notkins AL. Molecular cloning and identification of a receptor-type tyrosine phosphatase, IA-2, from human insulinoma. DNA and Cell Biology 199413 505-514.

10 Kawasaki E, Eisenbarth GS, Wasmeier C \& Hutton J. Autoantibodies to protein tyrosine phosphatase-like proteins in type 1 diabetes. Diabetes 199645 1344-1349.

11 Ziegler AG, Ziegler R, Vardi P, Jackson RA, Soeldner JS \& Eisenbarth GS. Life table analysis of progression to diabetes of anti-insulin autoantibody positive relatives of individuals with type 1 diabetes. Diabetes 198938 1320-1325.

12 Grubin CE, Daniels T, Toivola B, Landin-Olson M, Hagopian WA, $\mathrm{Li} \mathrm{L}$ et al. A novel radioligand binding assay to determine diagnostic accuracy of isoform-specific glutamic acid decarboxylase antibodies in childhood IDDM. Diabetologia 199437 344-350.

13 Verge CF, Gianani R, Kawasaki E, Yu L, Pietropaolo M, Jackson RA et al. Prediction of type 1 diabetes in first degree relatives using a combination of insulin, GAD and ICA 512 bdc/IA-2 autoantibodies. Diabetes $199645926-933$.

14 Hawkes CJ, Wasmeier C, Christie MR \& Hutton JC. Identification of the $37 \mathrm{kDa}$ antigen in IDDM as a tyrosine phosphatase-like protein (Phogrin) related to IA-2. Diabetes 199645 1187-1192.

15 Tisch R, Yang XD, Singer SM, Liblau RS, Fugger L \& McDevitt HO. Immune response to glutamic acid decarboxylase correlates with insulitis in non-obese diabetic mice. Nature $199336672-75$.

16 Harrison LC, Honeyman MC and DeAizpurua HJ. Inverse relation between humoral and cellular immunity to glutamic acid decarboxylase in subjects at risk of insulin-dependent diabetes. The Lancet 1993341 1365-1369.

17 Roep BO, Arden SD, de Vries RR \& Hutton JC. T-cell clones from a type 1 diabetes patient respond to insulin secretory granule proteins. Nature $1990345632-634$.

18 Roep BO, Kallan AA, Hazenbos WLW, Bruining GJ, Bailyes EM \& Arden SD. T-cell reactivity to a $38 \mathrm{kDa}$ insulin-secretory-granule protein in patients with recent onset type 1 diabetes. The Lancet 1991337 1439-1441.

19 Durinovic-Bello I, Hummel M \& Ziegler AG. Cellular immune response to diverse islet cell antigens in IDDM. Diabetes 199645 795-800.

20 Ellis TM, Schatz DA, Ottendorfer EW, Lan MS, Wasserfall C, Salisbury PJ et al. The relationship between humoral and cellular immunity to IA-2 in IDDM. Diabetes 199847 566-569.

Received 23 February 1999

Accepted 24 May 1999 